FEDERAL

RESERVE

BANK of

RESEARCH DIVISION

Working Paper Series

ST. LOUIS

\title{
Lobbying for a Common External Tariff from inside and out
}

\author{
Subhayu Bandyopadhyay \\ and \\ Sajal Lahiri
}

Working Paper 2012-061B

https://doi.org/10.20955/wp.2012.061

May 2016

\section{FEDERAL RESERVE BANK OF ST. LOUIS}

Research Division

P.O. Box 442

St. Louis, MO 63166

The views expressed are those of the individual authors and do not necessarily reflect official positions of the Federal Reserve Bank of St. Louis, the Federal Reserve System, or the Board of Governors.

Federal Reserve Bank of St. Louis Working Papers are preliminary materials circulated to stimulate discussion and critical comment. References in publications to Federal Reserve Bank of St. Louis Working Papers (other than an acknowledgment that the writer has had access to unpublished material) should be cleared with the author or authors. 
May 6, 2016

\title{
Possible Unintended Effects of Restrictions on Foreign Lobbying in a Customs Union*
}

\author{
By \\ Subhayu Bandyopadhyay $§$ and Sajal Lahiri $\ddagger$
}

\begin{abstract}
We consider the interactions between domestic lobbying and cross-border lobbying in a Customs Union (CU) in determining the Common External Tariff (CET). There are two types of cross-border lobbying: (i) lobbying from member-nation firms to the governments of other CU countries, and (ii) lobbying by firms from outside to the CU nation governments. Within this context, we analyze the effect of regulations on foreign lobbying on the equilibrium lobbying levels, and on the CET. If lobbying levels are strategic complements, tightening of restrictions on lobbying from outside the CU unambiguously reduces all types of lobbying. If non-CU firms are relatively large, the CET will rise in response to tighter regulations.
\end{abstract}

Keywords: Free Trade Area, Customs Union, Preferential Trading Agreements, Domestic lobbying, Cross-border lobbying, External tariffs.

JEL Classification: F13

$\S$ Federal Reserve Bank of St. Louis, Research Division, PO Box 442, St. Louis, MO 63166, U.S.A.; and Research Fellow at IZA, Bonn, Germany; E-mail: Subhayu.Bandyopadhyay@stls.frb.org $\ddagger$ Corresponding Author; Department of Economics, Southern Illinois University Carbondale, Carbondale, IL 62901-4515, U.S.A.; E-mail: lahiri@siu.edu

* The views expressed are those of the authors and do not necessarily represent official positions of the Federal Reserve Bank of St. Louis or of the Federal Reserve System. 


\section{Introduction}

Lobbying of a sovereign government by foreign interests is generally viewed with disdain. For example, in the US, in spite of the famous Citizens United ruling by the US Supreme Court in 2010, campaign contribution restrictions by foreign entities were not relaxed. Indeed, a challenge specifically on this ground by foreign plaintiffs was struck down in 2012 (see January 9, 2012, NYTimes, http://thecaucus.blogs.nytimes.com/2012/01/09/supremecourt-retains-ban-on-foreign-campaign-donations/). While it seems reasonable to think that national sovereignty should not be compromised by foreign interests, the economic implications of such restrictions are not as uncontroversial. For example, if domestic and foreign lobbying interests are on opposing sides of an issue, one may balance the other. If foreign interests are shut out of the process through regulation, the playing field tilts in favor of domestic lobbying interests. If, as Olson (1965) suggested, domestic consumers do not have incentives to engage in collective action, but producers have, the absence of foreign lobbying interests lead to unopposed lobbying by domestic producers. This is likely to raise protectionism in import competing industries at the cost of domestic consumers, and also lead to aggregate efficiency losses. We capture the essence of these ideas in the context of protectionism in a Customs Union $(\mathrm{CU})$, an arrangement where member nations trade freely within the bloc, while a common tariff is maintained on imports from outside the bloc (this tariff is referred to as Common External Tariff, CET). The European Union (EU) is a prominent example of a $\mathrm{CU}$, where there are restrictions on foreign lobbying of member nations, particularly in the form of campaign contributions. In some EU countries, there is a complete ban on campaign contributions from foreign firms, albeit loopholes and exceptions exist. Many economists worry that while a CU works towards enhancing trade between member nations, it may act as a barrier to multilateral free trade, because of its preferential treatment of member nations over non-member nations. ${ }^{1}$ Our contribution complements these concerns

\footnotetext{
${ }^{1}$ See, for example, Viner, 1950; Riezman, 1979; Gatsios and Karp, 1995.
} 
by highlighting the political economy aspect, where apparently reasonable regulations on foreign firms can further tilt the playing field. In particular, we consider non-cooperative lobbying of $\mathrm{CU}$ member nation governments by firms of both member and non-member nations. We analyze the properties of the lobbying equilibrium, and identify the conditions under which restrictions on lobbying on non-member nation firms are likely to raise the CET. If this happens, then the member-nation firms' preferential treatment (embedded in the design of the $\mathrm{CU}$ ) is amplified. Accordingly, a restriction on foreign lobbying reduces efficiency in the sense of moving the trading equilibrium away from multilateral free trade equilibrium.

Although the role of lobbying in influencing trade policy has been thoroughly researched, the effect of lobbying by foreign firms on domestic tariffs - the phenomenon of cross-border lobbying - has not received the amount of attention it deserves. Some recent papers have focused on this issue, but they do not capture some of the important characteristics of crossborder lobbying, particularly in the context of trading blocs. ${ }^{2}$ The political economy of trade policy in a $\mathrm{CU}$ has to take into account some distinctive factors. For example, one has to distinguish between cross-border lobbying from within a CU — lobbying by firms in one member country to the government of another member country — and lobbying from firms outside the $\mathrm{CU}$ to the governments of the $\mathrm{CU}$ member countries. In addition, lobbying done by non-CU firms have to focus on the multiple governments who are members of the CU. Indeed, cross-border lobbying is widely observed in the EU, where organizations such as Eurocommerce, EuroBio (European Association for Bio-industries), and Friends of Europe are extremely active in lobbying. Different types of cross-border lobby groups, however, have different objectives. CU member nation firms have the incentive to lobby for

\footnotetext{
${ }^{2}$ Although the context for North America Free Trade Area (NAFTA) is different, the incidence of crossborder lobbying is also well documented for these nations. For example, in the US case, data on lobbying firms, amount spent, and their clients are available in www.opensecret.org. Gawande et al. (2006) finds that foreign lobbies influence U.S. tariffs, while Stoyanov (2009) finds significant impact of foreign lobbying on Canadian trade policy. Attesting to such influence, a lobby firm in the U.S.A. writes on its website, "Holland \& Knight's International Trade Group represents the interests of ... foreign industries before the agencies of the United States Government, ..."(www.hklaw.com/id16048/mpgid4844/).
} 
a higher common external tariff (CET), while non-CU firms have the opposite incentive. The complementary and countervailing incentives of different $\mathrm{CU}$ and non-CU firms affect the CET in complicated ways. One of the contributions of this paper is to highlight the qualitative characteristics of the lobbying equilibrium that emerges in such a setting.

There are many ways of modeling lobbying. ${ }^{3}$ We adapt the campaign or political contributions approach. As will be clear later, our adaptation simplifies the equilibrium considerably. The model uses a two-stage game, where, in the first stage, firms decide on the levels of lobbying directed at CU member nation governments, while the CU chooses the CET in the second stage. Section 2 presents the model and the lobbying equilibrium. Section 3 considers the effect of greater restrictions on foreign lobbying on the equilibrium and on the CET. Section 4 presents a special case of oligopolistic competition, which allows us to delve deeper into the nature of the lobbying equilibrium, and throw more light on the conditions that determine whether lobbying restrictions may raise or reduce the CET. Section 5 concludes.

\section{$2 \quad$ The Model}

For simplicity, we consider a CU with two members, labeled $A$ and $B$. The rest of the world is labeled $C$. There is one non-numeraire good - we shall call this good "CU-importable" that is imported from $C$ by $A$ and $B$ and subject to a CET $t$, decided by the CU jointly. This decision is influenced by lobbying from the producers of this good in $A, B$ and $C$.

Domestic producers of the CU-importable in country $i(i=A, B)$ spend a total amount of $h_{i}$ on lobbying both governments. Consumers' surplus, domestic profits plus tariff revenue, in country $i$ is affected by the level of CET $t$; we denote it by $S_{i}(t)$ with $S_{i}^{\prime \prime}<0$. We assume

\footnotetext{
${ }^{3}$ There are many alternative approaches to modeling lobbying activities including the directly unproductive rent-seeking activities (DUPs) approach (Bhagwati, 1982), the tariff-formation function approach (Findlay and Wellisz, 1982), the political support function approach (Hillman, 1982), median voter approach (Mayer, 1984), the campaign contribution approach (Magee et al., 1989), and the political contributions approach (Grossman and Helpman, 1994). For an analysis of lobbying in the specific context of free trade agreements, see, for example, Grossman and Helpman, 1995; Panagariya and Findlay, 1996.
} 
that country $i$ 's government cares about not only social welfare, given by $S_{i}(t)-h_{i}$, but also about the amount of political contributions it receives.

Net profits of producers from countries $A$ and $B$ are given by $\pi^{i}(t)-h_{i}$ where $\pi^{i}(t)$ satisfied $\pi_{t}^{A}>0, \pi_{t}^{B}>0, \pi_{t}^{C}<0$, and $\pi_{t t}^{i} \geq 0(i=A, B, C)$.

Having introduced most of the important variables and functions, we proceed to the solution of the optimal level of CETs. We consider a two-stage game. In stage one, producers in the three countries decide on their lobbying levels by maximizing their profits. In stage 2, the CU authority decides on the level of CET by maximizing a weighted sum of the two governments' objective functions. To obtain a sub-game perfect equilibrium we work with backward induction. We now describe the two stages, starting with the second stage.

Let $h_{i j}(i=A, B, C ; j=A, B)$ be the proportion of profits that is spent on lobbying by firms in country $i$ on the government of country $j$. That is, $h_{A A} \pi^{A}$ and $h_{B B} \pi^{B}$ are domestic lobbying levels and $h_{A B} \pi^{A}, h_{B A} \pi^{B}, h_{C A} \pi^{C}$, and $h_{C B} \pi^{C}$, are the levels of cross-border lobbying. In the traditional campaign contribution approach to lobbying a la Grossman and Helpman (1994), contributions are lump-sum transfers and there are contribution schedules. However, one needs to impose the refinement of local truthfulness of the equilibrium. By specifying contributions in the forms of proportions of profits, we are kind of imposing truthfulness directly and bypassing a lot of the theoretical complications. Net profits (of the firm in country $i$ ) are given by

$$
\tilde{\pi}^{i}=\left(1-h_{i A}-h_{i B}\right) \pi^{i}(t), \quad i=A, B, C .
$$

We assume the existence of some adjustment costs associated with cross-border lobbying, possibly related to legal restrictions on foreign contributions to political funds. As a result, only a part of the amount spent on cross-border lobbying is actually received by the target of the lobbying as political contributions. Since restrictions on cross-border lobbying differ between those coming from within $\mathrm{CU}$ (i.e., from other member countries) and those coming 
from outside the $\mathrm{CU}$, we assume these costs to be different. The total amount of foreign funds received the two governments are $f_{B A}\left(h_{B A} \pi^{B}\right)$ and $\rho^{A} f_{C A}\left(h_{C A} \pi^{C}\right)$ for country $A$, and $f_{A B}\left(h_{A B} \pi^{A}\right)$ and $\rho^{B} f_{C B}\left(h_{C B} \pi^{C}\right)$ for country $B$, where the $f$-functions are assumed to be increasing and concave. The parameters $\rho^{A}$ and $\rho^{B}$ represent the degree of regulation on lobbying from outside the $\mathrm{CU}$ in countries $A$ and $B$ respectively. A decrease in $\rho^{i}$ represents an increase in regulation.

These assumptions are formally stated as

Assumption 1. $S_{j}^{\prime \prime}<0, \pi_{t}^{A}(t)>0, \pi_{t}^{B}(t)>0, \pi_{t}^{C}(t)<0, \pi_{t t}^{j}(t) \geq 0, f_{i j}^{\prime}>0$, and $f_{i j}^{\prime \prime}<0$ $(i=A, B, C, j=A, B, i \neq j)$.

The objective functions of the two CU member governments and the CU authority are

$$
\begin{gathered}
G^{A}=S^{A}(t)-\left(h_{A A}+h_{A B}\right) \pi^{A}+\rho^{A A} h_{A A} \pi^{A}+f_{B A}\left(h_{B A} \pi^{B}\right)+\rho^{A} f_{C A}\left(h_{C A} \pi^{C}\right), \\
G^{B}=S^{B}(t)-\left(h_{B A}+h_{B B}\right) \pi^{B}+\rho^{B B} h_{B B} \pi^{B}+f_{A B}\left(h_{A B} \pi^{A}\right)+\rho^{B} f_{C B}\left(h_{C B} \pi^{C}\right), \\
G^{C U}=\alpha G^{A}+(1-\alpha) G^{B} .
\end{gathered}
$$

In stage 2 of the game, the $\mathrm{CU}$ authority maximizes $G^{C U}$ with respect to $t$, giving rise to the first-order condition $\partial G^{C U} / \partial t=0$ as:

$$
\begin{aligned}
& \alpha S_{t}^{A}+(1-\alpha) S_{t}^{B}-\alpha\left(h_{A A}+h_{A B}\right) \pi_{t}^{A}+\alpha \rho^{A A} h_{A A} \pi_{t}^{A}+\alpha f_{B A}^{\prime} h_{B A} \pi_{t}^{B}+(1-\alpha) \rho^{B} f_{C B}^{\prime} h_{C B} \pi_{t}^{C} \\
& +\alpha \rho^{A} f_{C A}^{\prime} h_{C A} \pi_{t}^{C}-(1-\alpha)\left(h_{B A}+h_{B B}\right) \pi_{t}^{B}+(1-\alpha) \rho^{B B} h_{B B} \pi_{t}^{B}+(1-\alpha) f_{A B}^{\prime} h_{A B} \pi_{t}^{A}=0 .
\end{aligned}
$$

This simply states that the weighted average of the net marginal benefits of the two member countries is zero. In particular, the sixth and the seventh terms in (5) represent marginal costs of reduced contributions from country $C$ because of an increase in the CET.

From (5), we find the partial effects of lobbying on the CET, namely $\partial t / \partial h_{i j}(i, j=A, B)$ and $\partial t / \partial h_{C i}(i=A, B)$, and the effect of foreign- lobbying-restriction parameters on the CET, i.e., $\partial t / \partial \rho^{i}(i=A, B)$. The exact expressions for these effects are given in the appendix (see (A.1)-(A.5)). 
Intuitively, the firms in the CU member countries lobby for an increase in the CET, and the firms from outside the CU lobby in the opposite direction. From (A.1)-(A.5), we find that for domestic lobbying in country $i$ to have its desired effect, one must have $\rho^{i i}>1(i=A, B){ }^{4}$ Otherwise, an increase in lobbying will reduce the marginal benefit of increasing the CET for the CU authority, reducing the optimal level of the CET. Since cross-border lobbying are subject to adjustment costs, the effectiveness of such lobbying depends on the shape of the $f$-functions. For within-CU cross-border lobbying, say from Country $A$ to $B$ to be effective, a necessary condition is that $f_{A B}^{\prime}+h_{A B} \pi^{A} f_{A B}^{\prime \prime}>0$. Since the CU authority does not take into account the direct cost of lobbying from firms outside the CU, a similar condition is both necessary and sufficient, i.e., for lobbying from outside the CU, say from country $C$ to country $A$, to be effective a necessary and sufficient condition is that $f_{C A}^{\prime}+h_{C A} \pi^{C} f_{C A}^{\prime \prime}>0$.

An increase in restrictions against lobbying from outside the CU, i.e., a reduction in either $\rho^{A}$ or $\rho^{B}$, reduces the marginal costs of increasing the CET by reducing contributions from country $C$ and therefore increases the CET.

\subsection{The lobbying Equilibrium}

Each lobby group (firm) maximizes it profits given by (1) with respect to its lobbying levels to the two CU-country government, taking into account their effects on the CET as given by $(5)$.

$$
\begin{aligned}
\frac{\partial \tilde{\pi}^{A}}{\partial h_{A i}} & =\left(1-h_{A A}-h_{A B}\right) \pi_{t}^{A} \cdot \frac{\partial t}{\partial h_{A i}}-\pi^{A}=0, \quad(i=A, B), \\
\frac{\partial \tilde{\pi}^{B}}{\partial h_{B i}} & =\left(1-h_{B B}-h_{B A}\right) \pi_{t}^{B} \cdot \frac{\partial t}{\partial h_{B i}}-\pi^{B}=0, \quad(i=A, B), \\
\frac{\partial \tilde{\pi}^{C}}{\partial h_{C i}} & =\left(1-h_{C A}-h_{C B}\right) \pi_{t}^{C} \cdot \frac{\partial t}{\partial h_{C i}}-\pi^{C}=0, \quad(i=A, B),
\end{aligned}
$$

\footnotetext{
${ }^{4}$ Similar assumption is also made in Grossman and Helpman (1994).
} 
The second terms in (6)-(8) represent the marginal costs of lobbying and the first terms give the marginal benefit via an induced change in the level of CET. Clearly, a necessary condition for the equilibrium lobbying level to be positive is that lobbying has the necessary effect on the CET from each lobby group's point of view. From this and the observations made after (A.1)-(A.5), we derive the following property of the equilibrium levels of lobbying.

Lemma 1. A necessary condition for domestic lobbying in country $i$ to be positive is that $\rho^{i i}>1(i=A, B)$. As for cross border lobbying, a necessary condition for the equilibrium level of lobbying from country $i$ to country $j$ to be effective is that $f_{i j}^{\prime}+h_{i j} \pi^{i} f_{i j}^{\prime \prime}>0$ (i= $A, B, C, j=A, B, j \neq i)$.

Henceforth, we shall assume these necessary conditions to hold.

\section{Regulation and lobbying}

In this section, we shall examine the consequence of a tightening of the regulations against lobbying from outside the $\mathrm{CU}$ - represented by a reduction in $\rho^{A}$ and $\rho^{B}$ — on lobbying levels of firms within the $\mathrm{CU}$, those outside the $\mathrm{CU}$, and on the CET. For this exercise, we shall assume that countries $A$ and $B$ are completely symmetric, i.e., $\alpha=1 / 2, h_{A A}=h_{B B}$, $h_{A B}=h_{B A}, h_{C A}=h_{C B}, f_{A B}(\cdot)=f_{B A}(\cdot), f_{C A}(\cdot)=f_{C B}(\cdot), \rho^{A}=\rho^{B}$, and $\rho^{A A}=\rho^{B B}$.

From the two equations in (6), we first get using (A.1) and (A.3)

$$
\rho^{A A}=f_{A B}^{\prime}+h_{A B} \pi^{A} f_{A B}^{\prime \prime}
$$

and then differentiating it we obtain

$$
\pi^{A} d h_{A B}=-h_{A B} \pi_{t}^{A} d t
$$


From (5), we find

$$
d t=\sum_{i=A}^{C} \sum_{j=A}^{B} \frac{\partial t}{\partial h_{i j}} \cdot d h_{i j}-\frac{\alpha f_{C A}^{\prime} h_{C A} \pi_{t}^{C}}{\Delta_{1}} \cdot d \rho^{A}-\frac{(1-\alpha) f_{C B}^{\prime} h_{C B} \pi_{t}^{C}}{\Delta_{1}} \cdot d \rho^{B} .
$$

The last two terms above give the direct effects. A reduction $\rho^{A}$, for example, reduces the cost of increasing the CET in terms of a reduction in contributions from the firms in country C. This reduction in marginal costs would increase the equilibrium level of the CET. The other terms give effects via induced changes in the levels of lobbying.

Using symmetry and (9), equation (10) becomes

$$
\Delta_{3} d t=2 \frac{\partial t}{\partial h_{A A}} d h_{A A}+2 \frac{\partial t}{\partial h_{C A}} d h_{C A}-\frac{f_{C A}^{\prime} h_{C A} \pi_{t}^{C}}{\Delta_{1}} d \rho^{A}
$$

where $\Delta_{3}=1+2\left(\partial t / \partial h_{A B}\right) h_{A B} \pi_{t}^{A} / \pi^{A}>0$.

For analytical convenience, we shall isolate two effects on the solution of $h_{A A}$ and $h_{C A}$ : one via $t$ and the other via $\rho^{A}$ for given $t$. With this, (11) can be rewritten as

$$
\tilde{\Delta}_{3} \frac{d t}{d \rho^{A}}=2 \frac{\partial t}{\partial h_{A A}} \cdot \frac{\partial h_{A A}}{\partial \rho^{A}}+2 \frac{\partial t}{\partial h_{C A}} \cdot \frac{\partial h_{C A}}{\partial \rho^{A}}-\frac{f_{C A}^{\prime} h_{C A} \pi_{t}^{C}}{\Delta_{1}}
$$

where $\tilde{\Delta}_{3}=1+2\left(\partial t / \partial h_{A B}\right) h_{A B} \pi_{t}^{A} / \pi^{A}-2\left(\partial t / \partial h_{A A}\right) \cdot\left(\partial h_{A A} / \partial t\right)-2\left(\partial t / \partial h_{A A}\right) \cdot\left(\partial h_{A A} / \partial t\right)$.

We shall now introduce a few notations and these are

$$
\begin{aligned}
& \pi_{A A}^{A}=\left.\frac{\partial}{\partial h_{A A}}\left(\frac{\partial \pi^{A}}{\partial h_{A A}}\right)\right|_{t}, \pi_{C C}^{C}=\left.\frac{\partial}{\partial h_{C A}}\left(\frac{\partial \pi^{C}}{\partial h_{C A}}\right)\right|_{t}, \pi_{A \rho}^{A}=\left.\frac{\partial}{\partial \rho}\left(\frac{\partial \pi^{A}}{\partial h_{A A}}\right)\right|_{t} \\
& \pi_{A C}^{A}=\left.\frac{\partial}{\partial h_{C A}}\left(\frac{\partial \pi^{A}}{\partial h_{A A}}\right)\right|_{t}, \pi_{C A}^{C}=\left.\frac{\partial}{\partial h_{A A}}\left(\frac{\partial \pi^{C}}{\partial h_{C A}}\right)\right|_{t}, \pi_{C \rho}^{C}=\left.\frac{\partial}{\partial \rho}\left(\frac{\partial \pi^{C}}{\partial h_{C A}}\right)\right|_{t} .
\end{aligned}
$$

With the above notations, totally differentiating first equations in (6) and (8) we get

$$
\begin{aligned}
& \pi_{A A}^{A} d h_{A A}+\pi_{A C}^{A} d h_{C A}=-\pi_{A \rho}^{A} d \rho \\
& \pi_{C A}^{C} d h_{A A}+\pi_{C C}^{C} d h_{C A}=-\pi_{C \rho}^{C} d \rho
\end{aligned}
$$


where $\rho=\rho^{A}=\rho^{B}$ and

$$
\begin{aligned}
\pi_{A \rho}^{A} & =-\frac{\partial \Delta_{1}}{\partial \rho} \cdot \frac{\pi^{A}}{\Delta_{1}} \\
\frac{\partial \Delta_{1}}{\partial \rho} & =h_{C A} \pi_{t t}^{C}\left[f_{C A}^{\prime}+h_{C A} \pi^{C} f_{C A}^{\prime \prime}\left(\frac{\left(\pi_{t}^{C}\right)^{2}}{\pi^{c} \pi_{t t}^{C}}\right)\right], \\
\pi_{C \rho}^{C} & =-\frac{\pi^{C}}{\rho \Delta_{1}} \cdot\left[-\Delta_{1}+\rho \frac{\partial \Delta_{1}}{\partial \rho}\right] \\
& \left.=-\frac{\pi^{C}}{\rho \Delta_{1}} \cdot\left[S_{t t}^{A}-\left\{\left(\rho^{A A}-1\right) h_{A A}+\left(f_{A B}^{\prime}-1\right) h_{A B}\right)\right\} \pi_{t t}^{A}+f_{A B}^{\prime \prime}\left(h_{A B} \pi_{t}^{A}\right)^{2}\right] .
\end{aligned}
$$

Solving the above equation we get

$$
\begin{aligned}
\frac{d h_{A A}}{d \rho} & =\frac{-\pi_{C \rho}^{C} \pi_{C C}^{C}+\pi_{A \rho}^{A} \pi_{A C}^{A}}{\Delta_{4}}, \\
\frac{d h_{C A}}{d \rho} & =\frac{-\pi_{C \rho}^{C} \pi_{A A}^{A}+\pi_{A \rho}^{A} \pi_{C A}^{C}}{\Delta_{4}},
\end{aligned}
$$

where $\Delta_{4}=\pi_{A A}^{A} \pi_{C C}^{C}-\pi_{A C}^{A} \pi_{C A}^{C}>0$ from the a-stability conditions.

First of all, note that $\pi_{A A}^{A}<0$ and $\pi_{C C}^{C}<0$ from the second-order profit maximizing condition of the firms. Second, $\pi_{A C}^{A}>0$ and $\pi_{C A}^{C}>0$ if the CU-member country firms and the non-member firms are strategic complements in lobbying (this was the case in our example in section 4). Now, if $\partial \Delta_{1} / \partial \rho>0,{ }^{5}$ then both $\pi_{A \rho}^{A}>0$ and $\pi_{C \rho}^{C}>0$. In this case it follows from (13) and (14) that $d h_{A A} / d \rho>0$ and $d h_{C A} / d \rho>0$. That is, a tightening of the law of lobbying from outside Union will reduce lobbying by both groups.

Turning to the effect on the CET, it is best to focus on the case of strategic complementarity, which yields clean comparative statics for the lobbying levels. First note from (5) that a reduction in $\rho$ reduces the marginal cost of raising the CET for given levels of

\footnotetext{
${ }^{5}$ From the necessary condition stated in lemma 1 , it follows that $f_{C A}^{\prime \prime}$ cannot take a very large negative value. In fact, if $\left(\pi_{t}^{C}\right)^{2} /\left(\pi^{c} \pi_{t t}^{C}\right)<1$, then $f_{C A}^{\prime}+h_{C A} \pi^{C} f_{C A}^{\prime \prime}\left(\pi_{t}^{C}\right)^{2} /\left(\pi^{c} \pi_{t t}^{C}\right)>f_{C A}^{\prime}+h_{C A} \pi^{C} f_{C A}^{\prime \prime}>0$ (from lemma 1). Thus, a sufficient condition for $\partial \Delta_{1} / \partial \rho$ to be positive is that $\left(\pi_{t}^{C}\right)^{2} /\left(\pi^{c} \pi_{t t}^{C}\right)<1$. For the example in section 4 , it can be calculated that $\left(\pi_{t}^{C}\right)^{2} /\left(\pi^{c} \pi_{t t}^{C}\right)=1 / 72$.
} 
lobbying. This is the direct effect which raises the CET and it is given by the last term in (11). From (A.4), (A.5) and (8), we see that a reduction in $\rho$ reduces lobbying by firms from nation $C$, and this will tend to increase the level of the CET. This effect is represented by the second term in the right-hand-side of (11). As for the firms in the member countries, a reduction in $\rho$ reduces their lobbying too (under strategic complementarity), and this will tend to reduce the CET. This effect is given by the first term in the right-hand-side of (11). Clearly, for the CET to rise, this last effect has to be dominated by the other two effects. To see when this is likely to be the case, let us focus on (A.1), (A.4) and (11). These equations suggest that if the firms in the non-member countries have significant market share in the CU-member country market, i.e., $-\pi_{t}^{C}>>\pi_{t}^{A}$, then a reduction in $\rho$ would more likely increase the CET. ${ }^{6}$ Formally,

Proposition. Suppose that $f_{C A}^{\prime}+h_{C A} \pi^{C} f_{C A}^{\prime \prime}\left(\pi_{t}^{C}\right)^{2} /\left(\pi^{c} \pi_{t t}^{C}\right)>0$. Then, a tightening of regulations against lobbying by firms outside the Customs Union will:

- reduce lobbying by $C U$-member and non-member countries if the firms inside the $C U$ and those outside are strategic complements in lobbying, and

- increase the CET if the firms in the non-member countries have significant market share in the CU-member country market.

\section{An Oligopolistic model of CU}

The preceding section suggests that the effect of regulations on lobbying depends critically on whether firms view each others' lobbying efforts as strategic substitutes or complements. To throw more light on this issue, we present an oligopolistic model, where lobbying efforts of $\mathrm{CU}$ and non-CU firms are shown to be strategic complements.

\footnotetext{
${ }^{6}$ Note that $-\pi_{t}^{C}$ and $\pi_{t}^{A}$ are proportional to the output levels of the firms in country $C$ and $A$, respectively.
} 
There are three countries: $A$ and $B$ are members of a CU and a non-member country $C$. There are three goods: (i) one competitive numeraire good which is exported by countries $A$ and $B$, (ii) an imperfectly competitive good which is produced and consumed in countries $A$ and $B$ and not in any other countries, and (iii) a third good that is imperfect substitute of the second good and is produced in country $C$ and is exported to countries $A$ and $B$. Country $C$ is able to discriminate between the two markets, and the producer prices for the third good in the two markets are $p_{A}^{C}$ and $p_{B}^{C}$, respectively. As CU members, countries $A$ and $B$ apply a common tariff $t$ on imports from country $C$. The market for the second good is fully integrated in countries $A$ and $B$ and there is free trade between them as they are members of a $\mathrm{CU}^{7}$

The utility functions of representative consumers in countries $A$ and $B$ are:

$$
u^{i}\left(D_{i}, X_{i}^{C}, y_{i}\right)=\alpha D_{i}+\bar{\alpha} X_{i}^{C}-\frac{\beta\left(D_{i}\right)^{2}+\bar{\beta}\left(X_{i}^{C}\right)^{2}+2 \gamma D_{i} X_{i}^{C}}{2}+y_{i}, i=A, B
$$

where $y^{i}$ is the consumption of the numeraire good, $X_{i}^{C}$ is imports from country $C$, and $D_{i}$ is the consumption of the second good in country $i(i=A, B)$. We assume $\beta \bar{\beta}-\gamma^{2}>0$.

Inverse demand functions are derived from the above utility functions as:

$$
p=\alpha-\beta D_{A}-\gamma X_{A}^{C}, p=\alpha-\beta D_{B}-\gamma X_{B}^{C}, p_{i}^{C}+t=\bar{\alpha}-\bar{\beta} X_{i}^{C}-\gamma D_{i}, i=A, B
$$

Profits of the three firms in countries $A, B$ and $C$ are:

$$
\pi^{A}=\left(p-m_{A}\right) X_{A}, \pi^{B}=\left(p-m_{B}\right) X_{B}, \pi^{C}=\left(p_{A}^{C}-m_{C}\right) X_{A}^{C}+\left(p_{B}^{C}-m_{C}\right) X_{B}^{C},
$$

where $X_{A}$ and $X_{B}$ are the domestic production of second good in countries $A$ and $B$ respectively, and $m_{i}$ is the constant average and marginal cost of production in country $i$ $(i=A, B, C)$.

\footnotetext{
${ }^{7}$ By assuming market segmentation for country $C$ 's exports to the member countries, and product differentiation between the second and the third good, we are ruling out the issue of 'internal trade deflection' as in Richardson (1995).
} 
Since the market for good $D$ is fully integrated in countries $A$ and $B$, we have $D_{A}+D_{B}=$ $X_{A}+X_{B}$. Using this equality after summing the first two equations in (16), we get:

$$
p=\alpha-\frac{\beta}{2} \cdot\left(X_{A}+X_{B}\right)-\frac{\gamma}{2} \cdot\left(X_{A}^{C}+X_{B}^{C}\right) .
$$

From (16), (17), and (18), the Cournot-Nash profit-maximizing condition are:

$$
\begin{aligned}
p-m_{A} & =\frac{\beta X_{A}}{2}, \quad p-m_{B}=\frac{\beta X_{B}}{2} \\
2 \beta\left(p_{A}^{C}-m_{C}\right) & =\left(\beta \bar{\beta}-\gamma^{2}\right) X_{A}^{C}+\gamma^{2} X_{B}^{C}, \quad 2 \beta\left(p_{B}^{C}-m_{C}\right)=\left(\beta \bar{\beta}-\gamma^{2}\right) X_{B}^{C}+\gamma^{2} X_{A}^{C} .
\end{aligned}
$$

Solving the above equations we get

$$
\begin{aligned}
\Delta_{2} X_{A} & =6 \bar{\beta}\left(\alpha-m_{A}\right)-4 \gamma\left(\bar{\alpha}-m_{C}-t\right)-\left(3 \beta \bar{\beta}-2 \gamma^{2}\right)\left(m_{A}-m_{B}\right) / \beta, \\
\Delta_{2} X_{B} & =6 \bar{\beta}\left(\alpha-m_{B}\right)-4 \gamma\left(\bar{\alpha}-m_{C}-t\right)-\left(3 \beta \bar{\beta}-2 \gamma^{2}\right)\left(m_{B}-m_{A}\right) / \beta, \\
X_{A}^{C} & =X_{B}^{C}=2\left(\bar{\alpha}-t-m_{C}\right) /(3 \bar{\beta})-\gamma\left(X_{A}+X_{B}\right) /(3 \bar{\beta}), \\
D_{A} & =D_{B}=\left(X_{A}+X_{B}\right) / 2,
\end{aligned}
$$

where $\Delta_{2}=9 \beta \bar{\beta}-4 \gamma^{2}>0$.

From the above, we find

$$
\begin{aligned}
\frac{\partial X_{A}}{\partial t} & =\frac{\partial X_{B}}{\partial t}=\frac{4 \gamma}{\Delta_{2}}>0, \quad \frac{\partial X_{A}^{C}}{\partial t}=\frac{\partial X_{B}^{C}}{\partial t}=-\frac{6 \beta}{\Delta_{2}}<0, \\
\frac{\partial D_{A}}{\partial t} & =\frac{\partial D_{B}}{\partial t}=\frac{8 \gamma}{\Delta_{2}}>0, \quad \frac{\partial p}{\partial t}=\frac{2 \beta \gamma}{\Delta_{2}}>0, \quad \frac{\partial p_{A}^{C}}{\partial t}=\frac{\partial p_{B}^{C}}{\partial t}=-\frac{3 \beta \bar{\beta}}{\Delta_{2}}<0, \\
\frac{\partial \pi^{i}}{\partial t} & =\pi_{t}^{i}=\frac{4 \beta \gamma X_{i}}{\Delta_{2}}, i=A, B, \quad \frac{\partial \pi^{C}}{\partial t}=\pi_{t}^{C}=-\frac{\beta \bar{\beta} X_{A}^{C}}{\Delta_{2}}, \\
\left(\Delta_{2}\right)^{2} \pi_{t t}^{i} & =16 \beta \gamma^{2}, i=A, B, \quad\left(\Delta_{2}\right)^{2} \pi_{t t}^{C}=72 \beta^{2} \bar{\beta} .
\end{aligned}
$$

The above signs are as one would expect. Finally, we have

$$
S^{i}=\mathrm{CS}^{i}+t X_{i}^{C}+\pi^{i}, \quad i=A, B .
$$


That is, welfare is equal to consumers' surplus, tariff revenue and profits of domestic producer. Then, we have

$$
d S^{i}=-D_{i} d p-X_{i}^{C} d p_{i}^{C}+d \pi^{i}, \quad i=A, B
$$

from which we get for $i=A, B$

$$
\begin{aligned}
\Delta_{2} S_{t}^{i} & =-2 \beta \gamma D_{i}+3 \beta \bar{\beta} X_{i}^{C}-6 \beta t+4 \beta \gamma X_{i}, \\
\left(\Delta_{2}\right)^{2} S_{t t}^{i} & =-18 \beta^{2} \bar{\beta}-6 \beta \Delta_{2}<0 .
\end{aligned}
$$

We shall now examine the nature of strategic relationship between intra-CU and extraCU lobbying. In particular, we want to examine if lobbying by the two groups are strategic substitutes or strategic complements. For illustration purposes, we shall consider lobbying by firms in countries $\mathrm{A}$ and $\mathrm{C}$ to the government in country $\mathrm{A}$. As is well known, $h_{A A}$ and $h_{C A}$ are strategic substitutes (complements) if $\partial / \partial h_{A A}\left(\partial \tilde{\pi}^{C} / \partial h_{C A}\right)<0(>0$.

From (8) and assuming that $f_{i, j}^{\prime \prime} \simeq 0(i=A, B, C, j=A, B, i \neq j)$, we find: ${ }^{8}$

$$
\begin{aligned}
\frac{\partial}{\partial h_{A A}}\left(\frac{\partial \tilde{\pi}^{C}}{\partial h_{C A}}\right) & =\pi^{C}\left[\frac{2 \pi_{t t}^{C}}{\pi_{t}^{C}}-\frac{\pi_{t}^{C}}{\pi^{C}}+\frac{\pi_{t t}^{A}}{\pi_{t}^{A}}\right] \frac{\partial t}{\partial h_{A A}} \\
& =\frac{4 \gamma \pi^{C}}{\Delta_{2} X_{A}} \cdot \frac{\partial t}{\partial h_{A A}}>0 .
\end{aligned}
$$

That is $h_{A A}$ and $h_{C A}$ are strategic complements. Similarly, it can be shown that both $h_{C A}$ and $h_{C B}$ are strategic complements with lobbying by country $A$ and $B$ firms.

\section{Conclusion}

An emerging literature is throwing light on internationalization of the lobbying process, where firms of one nation lobby the government of another for greater protection in a common market, or for better access to a protected one. This contribution is one of the first to analyze

\footnotetext{
${ }^{8}$ The full expression is given by (A.6) in the appendix.
} 
the conflicting incentives for firms to lobby for and against protection in the context of a customs union like the EU. We identify three types of lobbying: domestic, cross-border of the intra-union type, and cross-border of a pure foreign type - where firms from outside the union lobby the member governments of a CU. We offer a model where the interdependence of these three types of lobbying and their effect on the CET are analyzed within the context of a tractable framework. In addition to throwing light on the qualitative nature of the lobbying equilibrium, we show that apparently sensible restrictions on foreign lobbying can be self-defeating. In particular, we show that under strategic complementarity in lobbying, greater restrictions on foreign lobbying reduces lobbying levels of all firms, yet the CET rises if foreign firms are relatively large. A practical implication of this finding is that in industries where $\mathrm{CU}$ imports are concentrated among a few large firms, restrictions on extra-CU lobbying may make the CU more protectionist vis a vis the rest-of-the-world. 


\section{References}

[1] Bandyopadhyay, Subhayu, Sajal Lahiri, and Howard J. Wall, 2012, Cross-border Lobbying in Preferential Trading Agreements: Implications for External Tariffs and Welfare, Review of International Economics, 20(5), 1034-1045.

[2] Bhagwati, J.N., 1982, Directly-Unproductive Profit-Seeking (DUP) Activities, Journal of Political Economy, 90, 988 - 1002.

[3] Findlay, R. and S. Wellisz, 1982, Endogenous Tariffs and the Political Economy of Trade Restrictions and Welfare, in: J. Bhagwati, ed., Import Competition and Response, University of Chicago.

[4] Gawande, K., P. Krishna and M. Robbins, 2006, Foreign Lobbies and US Trade Policy, Review of Economics and Statistics, 88, 563-71.

[5] Gatsios, K. and L. Karp, 1995, Delegation in a general equilibrium model of customs unions, European Economic Review, 39, 319-333.

[6] Grossman, G.M. and E. Helpman, 1994, Protection for Sale, American Economic Review 84, 833-50.

[7] Grossman, G.M. and E. Helpman, 1995, The Politics of Free Trade Agreements, American Economic Review, 85, 667-90.

[8] Hillman, A.L., 1982, Declining industries and political-support protectionist motives, American Economic Review, 72, 1180-87.

[9] Magee. S.P., Brock, W.A. and Young, L., 1989, Black hole tariffs and endogenous policy theory. Cambridge: Cambridge University Press.

[10] Mayer, W., 1984, Endogenous tariff formation, American Economic Review, 74, 970985. 
[11] Olson, Mancur, 1965, The Logic of Collective Action, Cambridge: Harvard University Press.

[12] Panagariya, A. and R. Findlay, 1996, A Political Economy Analysis of Free Trade Areas and Customs Unions, in: Feenstra, R.C., G.M. Grossman and D.A. Irwin, eds., The Political Economy of Trade Policy: Papers in Honor of Jagdish Bhagwati, MIT Press.

[13] Riezman, R.G., 1979, A 3x3 Model of Customs Unions, Journal of International Economics, 9, 341-354..

[14] Schiff, M. and L.A. Winters, 2003, Regional Integration and Development, World Bank, Oxford University Press.

[15] Stoyanov, A., 2009, Trade policy of a free trade agreement in the presence of foreign lobbying, Journal of International Economics, 77, 37-49.

[16] Viner, J., 1950, The Customs Unions Issue, Carnegie Endowment for International Peace, New York. 


\section{Appendix}

From (5), we find

$$
\begin{aligned}
\frac{\partial t}{\partial h_{A A}} & =-\frac{\alpha \pi_{t}^{A}\left(\rho^{A A}-1\right)}{\Delta_{1}}, \frac{\partial t}{\partial h_{B B}}=-\frac{(1-\alpha) \pi_{t}^{B}\left(\rho^{B B}-1\right)}{\Delta_{1}}, \\
\frac{\partial t}{\partial h_{B A}} & =-\frac{-(1-\alpha) \pi_{t}^{B}+\alpha \pi_{t}^{B}\left[f_{B A}^{\prime}+h_{B A} \pi^{B} f_{B A}^{\prime \prime}\right]}{\Delta_{1}}, \\
\frac{\partial t}{\partial h_{A B}} & =-\frac{-\alpha \pi_{t}^{A}+(1-\alpha) \pi_{t}^{A}\left[f_{A B}^{\prime}+h_{A B} \pi^{A} f_{A B}^{\prime \prime}\right]}{\Delta_{1}}, \\
\frac{\partial t}{\partial h_{C A}} & =-\frac{\alpha \rho^{A} \pi_{t}^{C}\left[f_{C A}^{\prime}+h_{C A} \pi^{C} f_{C A}^{\prime \prime}\right]}{\Delta_{1}}, \frac{\partial t}{\partial \rho^{A}}=-\frac{\alpha f_{C A}^{\prime} h_{C A} \pi_{t}^{C}}{\Delta_{1}}, \\
\frac{\partial t}{\partial h_{C B}} & =-\frac{(1-\alpha) \rho^{B} \pi_{t}^{C}\left[f_{C B}^{\prime}+h_{C B} \pi^{C} f_{C B}^{\prime \prime}\right]}{\Delta_{1}}, \frac{\partial t}{\partial \rho^{B}}=-\frac{(1-\alpha) f_{C B}^{\prime} h_{C B} \pi_{t}^{C}}{\Delta_{1}}
\end{aligned}
$$

where

$$
\begin{gathered}
\Delta_{1}=\alpha S_{t t}^{A}+(1-\alpha) S_{t t}^{B}-\alpha\left(h_{A A}+h_{A B}\right) \Pi_{t t}^{A}+\alpha \rho^{A A} h_{A A} \pi_{t t}^{A}+\alpha f_{B A}^{\prime} h_{B A} \pi_{t t}^{B}+\alpha \rho^{A} h_{C A} f_{C A}^{\prime} \pi_{t t}^{C} \\
+\alpha f_{B A}^{\prime \prime}\left[h_{B A} \pi_{t}^{B}\right]^{2}+\alpha \rho^{A}\left[h_{C A} \pi_{t}^{C}\right]^{2} f_{C A}^{\prime \prime}-(1-\alpha)\left(h_{B A}+h_{B B}\right) \pi_{t t}^{B}+(1-\alpha) \rho^{B B} h_{B B} \pi_{t t}^{B} \\
+(1-\alpha) f_{A B}^{\prime} h_{A B} \pi_{t t}^{A}+(1-\alpha) f_{A B}^{\prime \prime}\left[h_{A B} \pi_{t}^{A}\right]^{2}+(1-\alpha) \rho^{B} f_{C B}^{\prime} h_{C B} \pi_{t t}^{C}+(1-\alpha) \rho^{B} f_{C B}^{\prime \prime}\left[h_{C B} \pi_{t}^{C}\right]^{2},
\end{gathered}
$$

and the second-order condition of the CU authority's optimization problem gives $\Delta_{1}<0$.

From (8) we find

$$
\begin{aligned}
\frac{\partial}{\partial h_{A A}}\left(\frac{\partial \tilde{\pi}^{C}}{\partial h_{C A}}\right) & =\left[\left(1-h_{C A}-h_{C B}\right) \pi_{t t}^{C} \cdot \frac{\partial t}{\partial h_{C A}}-\pi_{t}^{C}+\frac{\pi^{C} \pi_{t t}^{A}}{\pi_{t}^{A}}-\frac{\pi^{C} Z}{\Delta_{1} \frac{\partial t}{\partial h_{C A}}}\right] \frac{\partial t}{\partial h_{A A}} \\
& =\pi^{C}\left[\frac{\pi_{t t}^{C}}{\pi_{t}^{C}}-\frac{\pi_{t}^{C}}{\pi^{C}}+\frac{\pi_{t t}^{A}}{\pi_{t}^{A}}-\frac{Z}{\Delta_{1} \frac{\partial t}{\partial h_{C A}}}\right] \frac{\partial t}{\partial h_{A A}}
\end{aligned}
$$

where

$$
\begin{gathered}
Z=\alpha h_{B A}^{2} \pi_{t t}^{B} f_{B A}^{\prime \prime} \pi_{t}^{B} \frac{\partial t}{\partial h_{C A}}+\alpha \rho^{A} \pi_{t t}^{C}\left[f_{C A}^{\prime}+h_{C A} \pi^{C} f_{C A}^{\prime \prime}+h_{C A}^{2} f_{C A}^{\prime \prime} \pi_{t}^{C} \frac{\partial t}{\partial h_{C A}}\right] \\
+2 \alpha \frac{\partial t}{\partial h_{C A}}\left[f_{B A}^{\prime \prime} h_{B A}^{2} \pi_{t}^{B} \pi_{t t}^{B}+\rho^{A} h_{C A}^{2} \pi_{t}^{C} f_{C A}^{\prime \prime} \pi_{t t}^{C}\right]+(1-\alpha) \frac{\partial t}{\partial h_{C A}}\left[h_{A B}^{2} \pi_{t t}^{A} f_{A B}^{\prime \prime} \pi_{t}^{A}+\rho^{B} h_{C B}^{2} \pi_{t t}^{C} f_{C B}^{\prime \prime} \pi_{t}^{C}\right] \\
+2(1-\alpha) \frac{\partial t}{\partial h_{C A}}\left[f_{A B}^{\prime \prime} h_{A B}^{2} \pi_{t}^{A} \pi_{t t}^{A}+\rho^{B} f_{C B}^{\prime \prime} h_{C B}^{2} \pi_{t}^{C} \pi_{t t}^{C}\right]+2 \alpha \rho^{A} h_{C A} f_{C A}^{\prime \prime}\left(\pi_{t}^{C}\right)^{2}
\end{gathered}
$$

